\title{
INNOVACIONES METODOLÓGICAS PARA LA SOCIEDAD DIGITAL: APRENDIZAJE BASADO EN PROYECTOS, APRENDIZAJE COLABORATIVO, FLIPPED CLASSROOM E INTELIGENCIAS MÚLTIPLES
}

\author{
Paula Lázaro Cayuso \\ Universidad Autónoma de Madrid
}

\section{RESUMEN}

Las tecnologías de la información y la comunicación pueden proporcionar los recursos necesarios para crear una revolución educativa en las aulas. En el momento histórico que vivimos se hace cada vez más exigente la necesidad de presentar nuevas alternativas o ideas y experiencias innovadoras con respecto al proceso de enseñanza y aprendizaje y el uso de las tecnologías de la información y la comunicación. Por ello, en esta propuesta educativa se plantean una serie de actividades en las que el Aprendizaje basado en proyectos es la base de unión de diferentes metodologías como el Aprendizaje colaborativo o el Flipped classroom, siempre teniendo en cuenta el desarrollo de las Inteligencias múltiples y la importancia que hay que brindar a las emociones en el desarrollo de las actividades en clase.

\section{PALABRAS CLAVE}

Aprendizaje basado en proyectos - Aprendizaje colaborativo - Flipped classroom - Inteligencias múltiples - Tecnologías de la información y la comunicación.

\begin{abstract}
Information and communication technologies can provide the resources needed to create an educational revolution in classrooms. In the historical moment that we live, it becomes increasingly demanding the need to present new alternatives or innovative ideas and experiences regarding the teaching and learning process and the use of information and communication technologies. Therefore, in this educational proposal, a series of activities are proposed in which Project based Learning is the basis for joining different methodologies such as Collaborative Learning or Flipped Classroom, always taking into account the development of multiple Intelligences and Importance that must be given to the emotions in the development of the activities in class.
\end{abstract}

\section{KEYWORDS}

Project based learning - Collaborative learning - Flipped classroom - Multiple intelligence - Information and communication technology. 


\section{INTRODUCCIÓN}

Con la incorporación de las tecnologías de la información y la comunicación, la sociedad está en un continuo cambio. La búsqueda rápida, la exploración y la discriminación dentro de la abundancia informativa serán habilidades cognitivas fundamentales en la sociedad que ya está llegando. Respecto de la palabra escrita y su relación con la imagen, es posible entrever que se trata de un nuevo equilibrio que ciertamente concede mayor lugar a las imágenes. Esto no quiere decir que la imagen desplace a la lectura, sino que se hace en soportes diferentes, con lógicas de lectura también diferentes, a saltos, en textos cortos, con enlaces a imágenes o caracteres icónicos. Se amplía así el abanico de los modos de escritura, que pasan a convivir en un marco híbrido. Parece que de unos años a esta parte se está realizando un esfuerzo por actualizar las aulas con ciertos recursos informáticos tales como las pizarras digitales, pero éstos, la mayor parte de las veces, se siguen utilizando dentro de una enseñanza tradicional. No se está aplicando realmente la tecnología para cambiar la forma de enseñar. La tarea docente adquiere relieve en una misión que no delega funciones sobre la tecnología, sino que se asocia con ella para ir un paso más allá (UNESCO, 2014).

Las tecnologías de la información y la comunicación pueden proporcionar los recursos necesarios para crear una revolución educativa en las aulas. Las operaciones de intercambio internalizan múltiples posibilidades de acceso a la información y a las relaciones sociales, generando comunidades flexibles que permiten componer alternativas de información y socialización, diversas y mutantes (Balardini, 2008). Se trata de conseguir que todos aprendan de la forma que más se ajuste a sus necesidades, que tengan la posibilidad de crear y aprender lo que realmente les interese de una manera lúdica y participativa.

En este caso, nos encontramos con un centro educativo regido desde sus comienzos por un Aprendizaje basado en proyectos en el que es escasa la aplicación de las TIC para el desarrollo de las clases. La unión de metodologías activas con las tecnologías de la información y la comunicación es una realidad que se debería propiciar para obtener una mejora educativa y es la que va a guiar el desarrollo de esta propuesta educativa.

\section{REFERENTE TEÓRICO:}

\subsection{Emociones}

El cerebro humano procesa la mayor parte de los estímulos externos de manera no consciente. Se calcula que los cinco sentidos procesan unos once millones de bits de información por segundo, de los cuales la gran mayoría lo hacen a través de la visión. No obstante, la conciencia no puede procesar más de cuarenta bits. La mayor parte de las decisiones que se adoptan tienen un responsable: el inconsciente (Bachrach, 2013, p.104).

Ferrés (2013) sostiene que el inconsciente tiene un papel muy importante en los procesos mentales. En la tradición occidental la filosofía, la antropología, la religión, la psicología y la pedagogía se han construido sobre la base de que el "Conócete a ti mismo" es el fundamento de la sabiduría y el secreto de la felicidad. En cambio, el paradigma dominante en esta cultura ha impedido y sigue impidiendo este conocimiento. 
Innovaciones metodológicas para la sociedad digital: aprendizaje basdo en proyectos, aprendizaje colaborativo, flipped classroom e inteligencias múltiples.

En los sentimientos emocionales intervienen muchos más mecanismos cerebrales que en los pensamientos. Las emociones crean una furia de actividad dedicada a un solo objetivo. Los pensamientos, a no ser que activen los mecanismos emocionales, no hacen esto (LeDoux, 1999, p. 337).

En otras épocas, instituciones como la escuela o la iglesia disfrutaron en parte de influencia gracias a utilizar en beneficio propio emociones negativas como el miedo. Una buena parte de su fracaso actualmente se debe a su incapacidad para utilizar en beneficio propio las emociones positivas y convertir sus productos en objeto de deseo. Sin emoción no hay movilización. (Ferrés, 2013, p. 43).

La central energética del cerebro está en el sistema límbico, el cual rige las emociones, genera los apetitos, los deseos, los impulsos y los estados de ánimo. Las emociones mueven mientras que los pensamientos sólo lo hacen si están conectados con las emociones, sólo nos movemos por aquello que amamos o que odiamos. El reto no consiste en sustituir emoción por razón, sino en integrarlas, en aprender a convertir la emoción en reflexión, a aprovechar la capacidad movilizadora de las emociones para activar la racionalidad y ejercitarse en actividades integradoras. Hoy la neurociencia confirma que, sin motivación, no hay aprendizaje (Ferrés, 2008, p. 61-63).

\subsection{Inteligencias múltiples}

La competencia cognitiva del hombre queda mejor descrita en términos de un conjunto de habilidades, talentos o capacidades mentales, que denominamos inteligencias. Todos los individuos poseen cada una de estas capacidades en un cierto grado, difiriendo en el grado de capacidad y en el modo de combinar estas capacidades (Gardner, 1993, p. 32-33). Existen ocho inteligencias:

Lingüística: es la capacidad de emplear de modo eficaz las palabras, manipulando la estructura o sintaxis del lenguaje, la fonética, la semántica, y sus dimensiones prácticas.

Cinético-corporal: es la habilidad para usar el propio cuerpo para expresar ideas y sentimientos. Incluye las particularidades de coordinación así como rasgos propios perceptivos y táctiles.

Lógico-matemática: es la capacidad de manejar números, relaciones, funciones, patrones lógicos y abstracciones de este tipo de manera eficaz.

Espacial: es la habilidad de apreciar la imagen visual y espacial, de representarse gráficamente ideas, y de sensibilizar la línea, la forma, el color, la figura, el espacio y sus interrelaciones.

Musical: es la capacidad de percibir, transformar y expresar las formas musicales.

Interpersonal: es la posibilidad de distinguir y percibir los estados emocionales, las intenciones, las motivaciones y sentimientos de otras personas.

Intrapersonal: es la habilidad de observación introspectiva, y de actuar consecuentemente sobre la base de este conocimiento. Se manifiesta en quienes poseen una autoimagen acertada, capacidad de autodisciplina, comprensión y valoración propia. 
Naturalista: es la facultad de reconocer y clasificar las numerosas especies de flora y fauna del entorno. También incluye la sensibilidad de otros fenómenos naturales como nubes o montañas y, en el caso de los individuos criados en un entorno urbano, la capacidad de distinguir formas inanimadas como coches, zapatillas, etc.

La existencia de este modelo conlleva una serie de implicaciones educativas, puesto que todos tenemos la posibilidad de desarrollar las inteligencias de una manera específica y lograr un nivel apropiado de competencia (Armstrong, 2006).

\subsection{Aprendizaje colaborativo}

Barkley, Cross y Mjor (2007) indican que el Aprendizaje colaborativo es una actividad estructurada de aprendizaje que aborda las principales preocupaciones relacionadas con la mejora en la forma de aprender de los alumnos. Implica activamente a los estudiantes, poniendo así en práctica la conclusión predominante de medio siglo de investigación sobre el desarrollo cognitivo. Ayuda a los estudiantes a apreciar múltiples perspectivas y a desarrollar competencias para abordar de modo colaborativo los problemas comunes de cara a una sociedad diversa y compromete a todos los alumnos valorando la perspectiva que cada uno puede aportar desde su experiencia personal.

Se considera que el Aprendizaje colaborativo, es otro de los postulados constructivistas que parte de concebir a la educación como proceso de socioconstrucción que permite conocer las diferentes perspectivas para abordar un determinado problema, desarrollar tolerancia en torno a la diversidad y pericia para reelaborar una alternativa conjunta. Los entornos de aprendizaje constructivista se definen como un lugar donde los alumnos deben trabajar juntos, ayudándose unos a otros, usando una variedad de instrumentos y recursos informativos que permitan la búsqueda de los objetivos de aprendizaje y actividades para la solución de problemas (Wilson, 1995, p. 27).

Por otra parte, el aprender en forma colaborativa permite al individuo recibir retroalimentación y conocer mejor su propio ritmo y estilo de aprendizaje, lo que facilita la aplicación de estrategias metacognitivas para regular el desempeño y optimizar el rendimiento. Además este tipo de aprendizaje incrementa la motivación, pues genera en los individuos fuertes sentimientos de pertenencia y cohesión, a través de la identificación de metas comunes y atribuciones compartidas, lo que le permite sentirse «parte de», estimulando su productividad y responsabilidad, lo que incidirá directamente en su autoestima y desarrollo (Calzadilla, 2002, p. 5)

El Aprendizaje colaborativo es un tipo de metodología docente activa en la que cada alumno construye su propio conocimiento y elabora sus contenidos desde la interacción que se produce en el aula. En un grupo colaborativo existe, pues, una autoridad compartida y una aceptación por parte de los miembros del grupo de la responsabilidad de las acciones y decisiones del grupo. Cada miembro del equipo es responsable total de su propio aprendizaje y, a la vez, de los restantes miembros del grupo (Iborra e Izquierdo, 2010, p. 223). Además Luque y Lalueza (2013), señalan que el aprendizaje mediante la colaboración puede ser entendido como "descubrimiento conjunto", pues se confrontan puntos 
Innovaciones metodológicas para la sociedad digital: aprendizaje basdo en proyectos, aprendizaje colaborativo, flipped classroom e inteligencias múltiples.

de vista distintos y se produce, por consiguiente, un conflicto sociocognitivo que actúa como motor del cambio.

\subsection{Flipped classroom}

Bergmann y Sams (2007), adoptaron el modelo Flipped classroom, que en español, se traduciría como Clase invertida. Dicho modelo busca invertir los roles y funciones del aula tradicional, esto es, que en clase se llevan a cabo procesos más personalizados a partir del desarrollo de las actividades y el espacio en casa se convierte en el lugar autónomo para el estudio de las lecciones determinadas.

Sin embargo,"invertir" una clase es mucho más que la edición y distribución de un vídeo o de cualquier otro tipo de contenidos multimedia. Se trata de un enfoque integral que combina la instrucción directa con métodos constructivistas, actuaciones de compromiso e implicación de los estudiantes con el contenido del curso y la mejora de su comprensión conceptual (Tourón y Santiago, 2013)

El modelo Flipped classroom permite validar nuevos escenarios en los que el aprendizaje autónomo y colaborativo cobre aun mayor importancia y vigencia, en la comprensión de que éste se desarrolla a partir de una participación activa por parte de sus actores. Además tiene un fuerte componente de responsabilidad y motivación por parte del estudiante para apropiar una información y transformarla en conocimiento a partir de la aplicación práctica en el aula. Así, el estudiante desarrolla su aprendizaje a partir de diversas situaciones que facilitan u optimizan el mismo, tales como sus experiencias, intereses y motivaciones, las problemáticas asociadas y las alternativas de solución (Perdomo, 2016, p. 2).

Para algunos estudiantes, la información puede llegar demasiado lentamente o tratar temas que ya saben; otros estudiantes pueden tener problemas para asimilar la información con la velocidad requerida, o pueden carecer de los conocimientos previos que necesitan para comprender los conceptos presentados. Aplicando el Flipped Classroom, los estudiantes ven las clases en casa, donde pueden acelerar con aquellos contenidos que ya entienden o se detienen para repetir las partes que no han comprendido bien. Tienen, además, la posibilidad de trabajar los contenidos que se perdieron la primera vez que el profesor los explicó. Este tipo de materiales pueden incorporar fácilmente representaciones visuales, como gráficos interactivos, vídeos 0 imágenes representativas, exámenes con feedback, etc. (Tourón y Santiago, 2015).

El profesorado deja de impartir clases magistrales, y pasa a tener un rol de facilitador o "guía" que ayuda al alumnado en clase, propone problemas para resolverlos entre todos y todas, realiza actividades grupales con distintas técnicas de trabajo, colaborativo, cooperativo, organiza debates, etc. El modelo Flipped classroom se centra en el alumno y en el desarrollo de competencias. Combina la instrucción directa, mediante vídeos, junto con metodologías constructivistas, que realiza en el aula. La tecnología y las actividades que se realicen en clase son los elementos esenciales en este modelo. Conocer el trasfondo pedagógico del modelo junto con el manejo de herramientas tecnológicas, serán cruciales para involucrar al alumno y conseguir el éxito en la utilización del mismo (Martín y Santiago, 2016) 


\subsection{Aprendizaje basado en proyectos}

Como dice Vergara (2015), los modelos de enseñanza diseccionan el saber en materias inconexas y lo ofrecen a los alumnos como algo inamovible y alejado de sus vidas, no produciendo los resultados esperados. Es necesario indagar estrategias (métodos) que partan de los intereses de los alumnos, los pongan en relación con los contenidos y destrezas que son relevantes en términos educativos, y que todo ello se ponga al servicio de un proyecto común.

Según INTEF (2015) el Aprendizaje basado en proyectos es una metodología que permite a los alumnos adquirir los conocimientos y competencias clave en el siglo XXI mediante la elaboración de proyectos que dan respuesta a problemas de la vida real. El aprendizaje y la enseñanza basados en proyectos forman parte del ámbito del "aprendizaje activo".

Larmer y Mergendoller (2011) describen el Aprendizaje basado en proyectos como un plato principal rico en contenidos curriculares y en competencias clave para la sociedad del siglo XXI (no como un postre en el que aplicar los contenidos vistos anteriormente) y establecen las siguientes características al definir el Aprendizaje basado en proyectos:

Pretende enseñar contenido significativo. Los objetivos para el aprendizaje de los estudiantes son explícitamente derivados de los estándares de aprendizaje y de las competencias clave del núcleo de las materias.

Requiere pensamiento crítico, resolución de problemas, colaboración, y diferentes formas de comunicación. Para responder a la pregunta clave que se establece en el proyecto y crear contenido de alta calidad, los estudiantes necesitan hacer mucho más que memorizar información. Tienen que usar habilidades complejas para ordenar sus ideas y aprender a trabajar como un equipo. Deben escuchar a los demás y exponer sus propias ideas de una forma clara, ser capaces de leer una amplia variedad de material, y realizar presentaciones. Estas habilidades, competencias y hábitos de la mente son a menudo conocidos como "habilidades del siglo XXI".

La investigación y la creación de algo nuevo son partes esenciales del proceso de aprendizaje. Los estudiantes preguntan cuestiones, buscan respuestas, y llegan a conclusiones, llevándoles a contribuir en algo nuevo: una idea, una interpretación, o un producto.

Está organizado alrededor de una pregunta clave abierta que enfoca el trabajo de los estudiantes y profundiza en su aprendizaje enmarcando cuestiones importantes, debates, retos o problemas.

Crea la necesidad de conocer contenidos esenciales y habilidades. El Aprendizaje basado en proyectos invierte el orden en el que la información y los conceptos son tradicionalmente presentados. El proyecto comienza presentando a los estudiantes conocimientos y conceptos que una vez adquiridos, se da a los estudiantes la oportunidad de aplicarlos. El Aprendizaje basado en proyectos comienza con la visión de lo que se espera construir. Esto crea un contexto y una razón para aprender y entender la información y los conceptos. 
Innovaciones metodológicas para la sociedad digital: aprendizaje basdo en proyectos, aprendizaje colaborativo, flipped classroom e inteligencias múltiples.

Permite cierto grado de elección a los alumnos. La parte principal del Aprendizaje basado en proyectos no es una experiencia totalmente dirigida donde ya está todo preestablecido. Los estudiantes aprenden a trabajar de forma independiente y a tener responsabilidad cuando se les pide tomar decisiones sobre cómo trabajarán y qué crearán. La oportunidad de tomar decisiones, y expresar lo que han aprendido por si mismos incrementa el compromiso en su propio aprendizaje.

Incluye procesos para la revisión y reflexión. Los estudiantes aprenden a dar y recibir respuestas para mejorar la calidad de los productos que crean, y se requiere que piensen sobre qué y cómo están aprendiendo.

Implica una audiencia pública. Los estudiantes presentan su trabajo a otras personas, más allá de sus compañeros de clase y profesor (presencial o de forma virtual). Esto incrementa la motivación de los estudiantes a realizar trabajo de alta calidad, y suma autenticidad al proyecto.

\subsection{Integración metodológica: Aprendizaje basado en proyectos, Aprendizaje colaborativo, Inteligencias múltiples, Flipped Classroom y Tecnologías de la información y la comunicación}

En el momento histórico que vivimos se hace cada vez más exigente la necesidad de presentar nuevas alternativas o ideas y experiencias innovadoras con respecto al proceso de enseñanza y aprendizaje y el uso de las tecnologías de la información y la comunicación. La habilidad más importante de la era digital que deben adquirir los estudiantes es la de aprender a aprender. Por tal motivo el aprendizaje ha pasado de ser una construcción individual de conocimiento a convertirse en un proceso social (Martí, Heydrich, Rojas y Hernández, 2010, p. 12).

"Las tecnologías permiten la transición de la lógica informacional del modelo uno-todos (modelo transmisivo) a la lógica de la comunicación todostodos (modelo interactivo)" (Aparici y Silva, 2012, p. 54). Esto hace que se pueda cambiar la forma de educar, donde el maestro no sea un mero transmisor de información, sino un guía que permita la construcción del aprendizaje por parte del alumnado.

La incorporación de las tecnologías de la información y la comunicación en la escuela es necesaria, puesto que la educación debe adaptarse a las exigencias de la sociedad. Sin embargo, la integración de las TIC en los procesos educativos no asegura por sí misma la educación de calidad (Alart, 2010).

A pesar de todos los avances conseguidos desde el punto de vista tecnológico, que hacen posible, por un lado, que la educación se abra a la realidad que la rodea, permitiendo un aprendizaje participativo, colaborativo, en comunidad, que atienda a las necesidades sociales, y, por otro, que la educación se ajuste a las necesidades y características individuales de cada persona; en la actualidad, siguen dándose formas de abordar la educación tradicionales en las que nada de esto ocurre y en las que las tecnologías son utilizadas simplemente como recurso para apoyar las explicaciones del profesor (Fundación Telefónica, 2012). Es necesario, por ello, utilizar metodologías activas que junto con las TIC sitúen al alumnado en el centro de su proceso de aprendizaje. 
Con el Aprendizaje basado en proyectos (ABP) asistido por las TIC los alumnos aprenden a resolver problemas y realizar tareas apoyándose y haciendo buen uso del poder de un conjunto de herramientas para potenciar la mente (Martí, Heydrich, Rojas y Hernández, 2010).

Se hace fundamental un Aprendizaje basado en proyectos y en el Aprendizaje colaborativo, que fomente la creatividad y el pensamiento crítico, y que ponga en práctica metodologías activas (Del Pozo, 2011). La distribución del espacio y del tiempo también ha de proporcionar oportunidades para que los niños aprendan de una manera cooperativa, lo que permite además de desarrollar la inteligencia interpersonal y crear un ambiente alegre y sociable en el aula, también beneficiar el rendimiento académico de los alumnos (García, Traver y Candela, 2001).

El desarrollo de las nuevas tecnologías y su utilización en el proceso educativo requiere del soporte que proporciona el Aprendizaje colaborativo, para optimizar su intervención y generar verdaderos ambientes de aprendizaje que promuevan el desarrollo integral de los aprendices y sus capacidades (Calzadilla, 2002, p. 7).

La aplicación de la teoría de las inteligencias múltiples en el aula nos ofrece un contexto mediante el cual se logra incrementar las interpretaciones y recursos que nos ofrecen las nuevas tecnologías (Armstrong, 2006). Inteligencias múltiples y TIC se tornan como visión innovadora de una pedagogía emergente que valora como oportunidad cierta los vínculos existentes entre ambas. Una oportunidad manifiesta en pro de una escuela comprensiva, inclusiva y normalizada que respeta la diversidad de las inteligencias (Martín, Cáceres e Hinojo, 2015, p. 10).

Cada vez somos más partícipes de experiencias educativas que apuestan acertadamente por poner en el centro de sus acciones al estudiante, dándole un protagonismo que le permite llegar por sí mismo al conocimiento ayudándose de las tecnologías, eligiendo las herramientas que desea emplear para buscar información, para sintetizarla, para editarla, incluso para publicarla (Calderero, Aguirre, Castellanos, Peris y Perochena 2014). Algunos ejemplos acerca de cómo personalizar la educación con apoyo de las TIC es el Flipped classroom (Hamdan, McKinight, McKinight y Arfstrom, 2013).

En una cultura digital, en la que las máquinas cumplen mejor que las personas la función de transmitir información, los educadores y educadoras deberían recuperar una función primordial: la de despertar el deseo, la de contagiar el entusiasmo, la de conseguir que el estudiante convierta en objeto de deseo aquello que pretende que sea objeto de conocimiento (Ferrés, 2008, p. 63).

\section{ACTIVIDADES}

Para la puesta en práctica de los objetivos marcados se ha escogido como ejemplo un proyecto realizado en $5^{\circ}$ de Educación Primaria. Este proyecto se compone de diferentes actividades de las que se han seleccionado las que mejor ejemplifican un proyecto trasversal en el que el Aprendizaje basado en proyectos ha servido como unión entre el Aprendizaje colaborativo, Inteligencias múltiples y la Clase invertida teniendo siempre en cuenta las Tecnologías de la información y la comunicación. Es importante señalar que no es necesaria la aplicación tanto 
Innovaciones metodológicas para la sociedad digital: aprendizaje basdo en proyectos, aprendizaje colaborativo, flipped classroom e inteligencias múltiples.

de todas estas metodologías a la vez, pues de lo que se trata es de escoger lo que mejor se adapte a la actividad que se quiere realizar.

En el proyecto, todas las actividades se presentan con los objetivos, competencias, contenidos, criterios de evaluación y estándares de aprendizaje aplicados, pues sin ellos una actividad carece de sentido. A la vez se muestra un cuadro en cada una de ellas para mostrar cuándo se ha utilizado el Aprendizaje colaborativo, las Inteligencias múltiples desarrolladas y la Clase invertida.

Hay que resaltar que la aplicación de las TIC es un medio para un fin, es decir, no hablamos de una asignatura de informática donde se apliquen conocimientos de otras áreas sino que hablamos de cómo utilizar las TIC en todas las áreas para la mejora educativa.

Para dar comienzo a este proyecto se les entregó un cuento desmontado que se muestra en la primera actividad.

\subsection{Actividad 1. Un cuento desmontado}

\begin{tabular}{|c|c|c|c|}
\hline \multicolumn{3}{|c|}{ APRENDIZAJE BASADO EN PROYECTOS } \\
\hline \hline \multicolumn{3}{|c|}{ APRENDIZAJE COLABORATIVO } \\
\hline \hline \multicolumn{3}{|c|}{ INTELIGENCIAS MÚLTIPLES } \\
\hline Lingüistica & Cinético-corporal & Espacial & Interpersonal \\
\hline
\end{tabular}

Esta actividad debía cambiar la organización de la clase con una agrupación en forma de "U" a grupos de 4 mesas. A cada grupo se le dio un sobre que contenía todas las palabras necesarias para la creación de una historia.

Se les dejó total libertad para que cada grupo actuase como viese necesario para conseguir montar el cuento. Muchos optaron al principio por extender todas las palabras y tener una visión de conjunto.

En la segunda sesión, un grupo explicó al resto que ellos estaban clasificando las palabras según sus características. A partir de ahí cada grupo hizo la clasificación que le parecía mejor.

Finalmente se dieron cuenta todos los equipos que agrupando las palabras por nombres, determinantes, verbos, etc, el cuento se montaba rápido.

Para la composición final se utilizó la aplicación online "linoit.com" en la que los grupos iban subiendo los párrafos que habían conseguido encajar para entre toda la clase volver a montar el cuento.

En este cuento se explicaba que un niño y una niña habían ido en busca de un tesoro. Todas las pistas les habían llevado al pueblo de Arlanzón (Burgos) en dónde desaparecieron y no se les volvió a ver jamás. Por suerte, habían dejado pistas por el pueblo para que otros niños y niñas pudiesen encontrar el tesoro.

Aplicación TIC: Para esta actividad se utilizaron 4 portátiles del colegio, cada grupo utilizaba uno y así las posibles frases que fuesen saliendo las iban escribiendo. Además estos portátiles se utilizaron para subir los párrafos que 
habían conseguido montar cada grupo a "linoit.com", de esta manera se facilitaba la composición final del cuento.

\subsection{Actividad 2. El trayecto}

\begin{tabular}{|c|c|c|c|c|}
\hline \multicolumn{5}{|c|}{ APRENDIZAJE BASADO EN PROYECTOS } \\
\hline \multicolumn{5}{|c|}{ APRENDIZAJE COLABORATIVO } \\
\hline \multicolumn{5}{|c|}{ INTELIGENCIAS MÚLTIPLES } \\
\hline Lingüística & Lógico-matemática & Espacial & Interpersonal & Intrapersonal \\
\hline
\end{tabular}

Después del cuento desmontado se decidió ir a Arlanzón de acampada para buscar el tesoro. Para esto había que conocer bien la zona, aprender sobre ella y así habría más posibilidades de encontrarlo.

Lo primero que se sugirió hacer es conocer el trayecto que íbamos a realizar. Se utilizó el proyector de la clase para poner Google Maps y marcar el recorrido que iba a hacer el autobús, ver las provincias por las que pasaba, etc. Uno de los niños preguntó en qué punto del camino se encontrarían al llevar una hora y media y todos se pusieron manos a la obra para averiguar dónde sería (individualmente o por parejas, según prefiriesen). Descubrieron dos formas de hacerlo: si el trayecto se realizaba en dos horas y si llevaban hora y media de camino, significaba que llevaban tres cuartas partes de éste. Otra de las formas fue averiguarlo a través de la velocidad, suponiendo que el autobús iría a $100 \mathrm{~km} / \mathrm{h}$ por la autopista y llevaba una hora y media, habría hecho unos $150 \mathrm{~km}$.

Aplicación TIC: En esta actividad el uso de Google Maps era el centro de atención, pues permitía ver a tiempo real el trayecto que harían de una forma dinámica. La proyección del mapa en la pizarra permitió que entre todos marcasen las zonas de interés, las diferentes partes del viaje, etc.

\subsection{Actividad 3. Baja Edad Media}

\begin{tabular}{|c|c|c|c|}
\hline \multicolumn{4}{|c|}{ APRENDIZAJE BASADO EN PROYECTOS } \\
\hline \multicolumn{4}{|c|}{ APRENDIZAJE COLABORATIVO } \\
\hline \multicolumn{4}{|c|}{ CLASE INVERTIDA (FLIPPED CLASSROOM) } \\
\hline \multicolumn{4}{|c|}{ INTELIGENCIAS MÚLTIPLES } \\
\hline Lingüística & Espacial & Interpersonal & Intrapersonal \\
\hline
\end{tabular}

La primera actividad que se propuso es la búsqueda de información sobre Arlanzón en casa. Esta búsqueda se puso en común en clase para debatir sobre qué temas se iba a investigar. Uno de estos temas fueron las iglesias románicas que existían por la zona, lo que llevo a saber que las iglesias románicas pertenecían a la Baja Edad Media por lo que esta es la época que se escogió como tema de investigación. 
Innovaciones metodológicas para la sociedad digital: aprendizaje basdo en proyectos, aprendizaje colaborativo, flipped classroom e inteligencias múltiples.

Para el desarrollo de este tema se pidió a los niños que buscasen en casa hechos importantes que tuviesen lugar durante la Baja Edad Media y los situasen en una línea del tiempo. Se les dejó varios días para la búsqueda de información.

El siguiente paso fue la puesta en común de los hechos que habían encontrado. Se hizo en la pizarra digital una línea del tiempo donde se copiaban todos los que se iban diciendo. Si a alguien le faltaba alguno, lo iba añadiendo en su hoja.

Cuando terminaron la puesta en común hicieron agrupaciones de hechos históricos en la pizarra, cada una sobre un tema. Los niños de la clase se repartieron los temas según quisieron, de manera que cada grupo de niños se encargaría de uno de los temas. Para el siguiente día deberían buscar información en casa sobre el tema que habían escogido.

Se utilizaron varios días para la puesta en común y el trabajo en equipo. La dinámica que seguían era la de buscar información en casa, ponerla en común con su grupo en clase, analizar la información que les faltaba, volver a buscar y volver a poner en común las veces que hiciera falta hasta conseguir el trabajo esperado.

Cada grupo expuso el trabajo realizado, de modo que mientras un grupo exponía, el resto de compañeros apuntaban la información en su cuadernillo de investigación.

El siguiente día de trabajo se les entregó un dossier con la información de sus compañeros junto con un cuaderno en blanco con títulos donde se les pedía cierta información de la recopilada en el cuadernillo de investigación y en el dossier. De esta manera, tenían que hacer una síntesis entre la información que ellos habían recopilado y la de sus compañeros, para volcarla en el cuaderno en blanco, que posteriormente recogió la maestra para su evaluación.

Aplicación TIC: En esta actividad las TIC se utilizaron para poner el material en común sobre lo que habían encontrado y para la realización de los cuadernos con los portátiles de clase. La aplicación más importante fue la que hicieron los propios alumnos de forma libre: por una parte buscando información en internet relativa al tema, por otra utilizando el tratamiento de textos de forma adecuada y finalmente con la exposición de los materiales encontrados, mediante el uso de Power Point, videos, canciones, etc. Esta parte era fundamental para ver cómo les habían impactado las TIC y el uso que hacían de ellas.

\subsection{Actividad 4. Los ángulos}

\section{APRENDIZAJE BASADO EN PROYECTOS}

\section{APRENDIZAJE COLABORATIVO}

INTELIGENCIAS MÚLTIPLES

Cinético-corporal

Lógico-matemática

Espacial

Intrapersonal

Con esta actividad de introducción se buscaba que experimentasen con el concepto de ángulo. Para ello se les dio plastilina y trozos de pajitas para que creasen los polígonos regulares que ya habían visto en clase para trabajar el 
ángulo en 3D. A partir de los modelos fueron viendo los elementos de un ángulo, la clasificación de los ángulos y su medida. Para terminar la actividad dibujaron en el papel la figura que habían creado, haciendo una tabla con su número de ángulos, de lados, de vértices, tipo de ángulo, etc. Para terminar se hicieron fotos a las figuras creadas.

Aplicación TIC: En esta actividad la aplicación de las TIC se realizó con la utilización de un móvil para hacer fotos a los trabajos y poder tenerlos en cuenta en la siguiente actividad y para exponerlos en el centro educativo.

\subsection{Actividad 5. El Gótico y el Románico}

\begin{tabular}{|c|c|c|c|}
\hline \multicolumn{3}{|c|}{ APRENDIZAJE BASADO EN PROYECTOS } \\
\hline \hline \multicolumn{3}{|c|}{ APRENDIZAJE COLABORATIVO } \\
\hline \multicolumn{3}{|c|}{ INTELIGENCIAS MÚLTIPLES } \\
\hline Lingüistica & Espacial & Interpersonal & Intrapersonal \\
\hline
\end{tabular}

Con motivo de las iglesias que iban a ver, observarían también las diferencias entre el Románico y el Gótico. Se trabajó proyectando características muy generales de ambos estilos entremezcladas. A la vez se proyectaron imágenes de una iglesia gótica y otra románica, para mediante la observación colocar individualmente las características de cada estilo. Cuando terminaron pusieron en común lo que habían visto con el de al lado y debatieron por qué habían puesto unas en un sitio y otras en otro. Cuando las parejas lo tuvieron claro se cambiaron con otras parejas para la puesta en común.

La segunda parte de la actividad consistió en subrayar directamente en la pizarra las palabras que no entendiesen de las características. Se crearon unas tarjetas con el vocabulario nuevo que estaban aprendiendo, las cuales a la vuelta tenían una imagen de lo que significaba cada palabra. Por ejemplo detrás de la palabra arco de medio punto había una imagen de un arco de medio punto. La maestra fue pasando por cada uno, resolviendo las dudas que tenían con la ayuda de las tarjetas para que fuese lo más visual posible. Al final de la actividad se proyectaron imágenes de iglesias góticas e iglesias románicas, que debían identificar, explicando su elección, además se utilizó las figuras realizadas en la actividad 4 (realización de polígonos en 3D) para ver similitudes entre sus polígonos y los polígonos utilizados en las iglesias.

Aplicación TIC: Para esta actividad se hizo imprescindible el uso del proyector y el ordenador para ver las imágenes y las características en la pizarra.

\subsection{Actividad 6. Chirigota}


Innovaciones metodológicas para la sociedad digital: aprendizaje basdo en proyectos, aprendizaje colaborativo, flipped classroom e inteligencias múltiples.

\begin{tabular}{|c|c|c|c|c|}
\hline \multicolumn{5}{|c|}{ APRENDIZAJE BASADO EN PROYECTOS } \\
\hline \multicolumn{5}{|c|}{ APRENDIZAJE COLABORATIVO } \\
\hline \multicolumn{5}{|c|}{ CLASE INVERTIDA (FLIPPED CLASSROOM) } \\
\hline \multicolumn{5}{|c|}{ INTELIGENCIAS MÚLTIPLES } \\
\hline Lingüística & Espacial & Musical & Interpersonal & Intrapersonal \\
\hline
\end{tabular}

Durante la investigación de Arlanzón se descubrió que en las fechas en las que iríamos a visitar el pueblo se realizaría un carnaval con chirigotas, por lo que se decidió realizar una. Para realizarlo se empezó por una introducción sobre el tipo de rima que se utiliza en las Aleluyas, poniendo varios ejemplos.

La segunda parte de este trabajo se realizó con el juego de La Oca. Consistía en inventarse el mismo tipo de rima que con las Aleluyas para así fomentar la imaginación y la creación de textos en verso. Cada niño se inventó las rimas que quiso para después hacer una exposición del trabajo de cada uno.

Estaban preparados para el siguiente paso, inventar sus propias rimas con el tema y la música elegida en consenso entre toda la clase para la chirigota.

Vinieron con muchísimas propuestas y entre todos fueron cogiendo de uno y de otro las que más gustaban para hacer una en común. El resultado fue brillante, una chirigota compuesta por ellos en pocos días.

Aplicación TIC: Para el desarrollo de esta actividad se utilizó el ordenador de clase junto con el proyector pues es una forma muy rápida de ir añadiendo versos en el ordenador mientras que todos veían el resultado obtenido. Además al utilizar esta técnica cada día se imprimía y se entregaba una copia a cada uno para poder trabajar en casa. El ordenador también se utiliza para escuchar la canción y ensayar la chirigota.

\subsection{La acampada en Arlanzón.}

\begin{tabular}{|l|l|c|c|c|c|c|c|}
\hline \multicolumn{7}{|c|}{ APRENDIZAJE BASADO EN PROYECTOS } \\
\hline \multicolumn{7}{|c|}{ APRENDIZAJE COLABORATIVO } \\
\hline \multicolumn{7}{|c|}{ INTELIGENCIAS MÚLTIPLES } \\
\hline Lingüística & $\begin{array}{c}\text { Cinético- } \\
\text { corporal }\end{array}$ & $\begin{array}{c}\text { Lógico- } \\
\text { matemática }\end{array}$ & Espacial & Musical & Interpersonal & Intrapersonal & Naturalista \\
\hline
\end{tabular}

Este proyecto termina con una acampada de 5 días en Arlanzón (Burgos). Esta parte del proyecto es de suma importancia pues se aplican los conocimientos aprendidos en clase. Siempre se busca un contacto con la naturaleza, realizando caminatas por las inmediaciones y viendo en persona todo lo aprendido hasta ese momento. Además se trabaja mucho a nivel emocional con los niños y niñas pues es una convivencia de 24 horas durante 5 días en las que están en continua comunicación entre ellos, expresan lo que sienten, se trabajan problemas, relaciones entre ellos, se realizan juegos, etc. 
Este viaje supone un crecimiento personal grande al separar a los niños y niñas de sus padres y su círculo de confort habitual. Ganan independencia, madurez y confianza en sí mismos.

De forma resumida se explica a continuación alguna de las actividades:

Visita de la Iglesia de Arlanzón: En ella se pudo poner en práctica los conocimientos aprendidos en clase del arte románico y sus diferencias con el gótico.

Senderismo por los alrededores de Arlanzón: Se realizó uno de los días una ruta en donde se pudo observar las plantas que se habían estudiado en clase durante el proyecto.

Carnaval: Se realizó un carnaval en el pueblo en donde se disfrazaron y cantaron las chirigotas que habían compuesto.

Veladas nocturnas: En ellas se aprovechó para hacer marchas nocturnas, observación de las estrellas y hacer juegos nocturnos de confianza y compañerismo en donde se buscó la cohesión grupal.

\section{CONCLUSIONES}

Hay que resaltar que el uso de las TIC ha sido un recurso más dentro de las aulas. Su aplicación no tiene que verse cómo una única forma de impartir las clases pues la educación necesita de una gran variedad de recursos, utilizados en mayor o menor medida dependiendo de lo que requiera cada actividad. Reflexionar sobre cómo aplicar las TIC debe estar siempre presente.

Uno de los puntos a mejorar es la organización entre los docentes para el desarrollo de las actividades que utilicen recursos TIC. Es habitual que cuando se implanta algo innovador en un centro la organización sea algo a mejorar. Hay que tener presente la necesidad de las reuniones entre los docentes, pues en ellas se plantea la temporalización, los objetivos a seguir, los fallos a mejorar, las propuestas, etc.

La aplicación de las actividades planteadas en esta propuesta ha sido altamente gratificante. Se ha observado una reducción del tiempo utilizado en las clases, permitiendo utilizarlo para otros aspectos. El uso de las TIC mediante metodologías activas ha supuesto una mayor conexión con el alumnado y ha aumentado su implicación, participación, motivación e interés en las clases impartidas.

Con todo lo expuesto podemos concluir que el uso de las TIC está estrechamente vinculado al Aprendizaje basado en proyectos, al Aprendizaje colaborativo, a las Inteligencias múltiples y a la Flipped classroom consiguiendo en el alumnado un aumento significativo de la ilusión y las ganas de aprender.

\section{REFERENCIAS BIBLIOGRÁFICAS}

Alart, N. (2010). Una mirada a la educación desde las competencias básicas y las inteligencias múltiples. Aula de innovación educativa, 17(188), 61-65.

Aparici, R. y Silva, M. (2012). Pedagogía de la interactividad. Comunicar, 19(38), 51-58.

Armstrong, T. (2006). Inteligencias múltiples en el aula. Barcelona: Paidós. 
Innovaciones metodológicas para la sociedad digital: aprendizaje basdo en proyectos, aprendizaje colaborativo, flipped classroom e inteligencias múltiples.

Balardini, S. (2008). De deejays, floggers y ciberchabones, En R. Bendit, M. Hahn, y A. Miranda. Los jóvenes y el futuro. Procesos de inclusión social y patrones de vulnerabilidad en un mundo globalizado, Buenos Aires: Prometeo.

Barkley, E. F., Cross, K. P., \& Major, C. H. (2007). Técnicas de aprendizaje colaborativo: Manual para el profesorado universitario. Madrid: Ministerio de educación y ciencia y ediciones Morata.

Brachrach, E. (2013). Ágilmente: aprende cómo funciona tu cerebro para potenciar tu creatividad y vivir mejor, Barcelona: Conecta.

Bergmann, J., y Sams, A. (2007). Flip your classroom: reach every student in every class every day. ASCD.

Calderero, J., Aguirre, A. M., Castellanos, A., Peris, R. M., y Perochena, P. (2014). Una nueva aproximación al concepto de educación personalizada y su relación con las TIC. Teoría de la Educación; Educación y Cultura en la Sociedad de la Información, 15(2), 131.

Calzadilla, M. E. (2002). Aprendizaje colaborativo y tecnologías de la información y la comunicación. Revista Iberoamericana de educación, 1(10), 1-10.

Del Pozo, M. (2011). Inteligencias Múltiples en acción. Barcelona: Tekman Books.

Ferrés, J. (2008). La educación como industria del deseo, Barcelona: Gedisa.

Ferrés, J. (2013). Las pantallas y el cerebro emocional, Barcelona: Gedisa.

García, R., Traver, J. A., \& Candela, I. (2001). Aprendizaje cooperativo. Fundamentos, características y técnicas. Madrid: CCS-ICCE.

Gardner, H. (1993). Inteligencias múltiples. La teoría en la práctica, Barcelona: Paidós.

Hamdan, N., McKnight, P., McKnight, K., \& Arfstrom, K. (2013). A white paper based on the literature review titled $A$ Review of flipped learning. Madrid: Pearson. Flipped Learning Network.

Iborra, A., e Izquierdo, M. (2010). ¿Cómo afrontar la evaluación del aprendizaje colaborativo? Una propuesta valorando el proceso, el contenido y el producto de la actividad grupal. Revista General de Información y Documentación, 20, 221-241.

INTEF. (2015). ABP. Aprendizaje basado en proyectos. Bloque 1. Definición $A B P$. Recuperado http://formacion.educalab.es/mod/imscp/view.php?id=21435.

Larmer, J. y Mergendoller, J. (2011). The main course, not dessert. Buck Institute for Educación. Recuperado de https://www.bie.org/object/document/main_course_not_dessert.

Ledoux, J. (1999). El cerebro emocional. Barcelona: Planeta y Ariel.

Luque, M. J. y Lalueza, J. L. (2013). Aprendizaje colaborativo en comunidades de práctica en entornos de exclusión social. Revista de educación, (362), 402-428. 
Martí, J. A., Heydrich, M., Rojas, M., y Hernández, A. (2010). Aprendizaje basado en proyectos: Una experiencia de innovación docente. Revista Universidad EAFIT, 46(158), 11-21.

Martín, D. y Santiago, R. (2016). Flipped Learning en la formación del profesorado de secundaria y bachillerato. Formación para el cambio. Contextos educativos: Revista de educación, (1), 117-134.

Martín, M., Cáceres, M. P., e Hinojo, M. A. (2015). Visiones en torno a la integración de las TIC e inteligencias múltiples. Universidad de Málaga, $1-13$.

Perdomo, W. (2016). Estudio de evidencias de aprendizaje significativo en un aula bajo el modelo Flipped Classroom. Edutec. Revista Electrónica de Tecnología Educativa, 0(55).

Tourón, J y Santiago, R. (2015). El modelo Flipped Learning y el desarrollo del talento en la escuela. Revista de educación, (368), 174-195.

UNESCO. (2014). Políticas TIC en los sistemas educativos de América Latina, Buenos Aires.

Vergara, J. (2015). Aprendo porque quiero. El Aprendizaje Basado en Proyectos $(A B P)$, paso a paso, España: Ediciones SM.

Wilson, J. (1992). Cómo valorar la calidad de la enseñanza. Madrid: Paidós. 